\title{
Using Biceps Autograft in Reconstruction of Labral Defect in Recurrent Shoulder Dislocation
}

\author{
Yousef Khair*, Ayman Mustafa, Saab Mestarihi, Malek Ghnaimat, Gaith Abu Nwar, Sana'a Haddadin, Silvana De \\ Giorgi
}

Department of Orthopedics, Royal Medical Services, Jordan

*Corresponding author: Yousef Khair, Department of Orthopedics, Royal Medical Services, Zahran street, Zahran Post office mail code 11183, Amman, Jordan

\begin{abstract}
Background: Recurrent anterior shoulder dislocation is a very common problem that face the orthopedic surgeon, which affects young people in their life, especially the professional workers or athletes and military persons. They may need either arthroscopic or open procedure to obtain a stable shoulder. Arthroscopic Bankart repair is the most popular technique used, but there is a high recurrence rate in patients either with labral tear or glenoid bone loss more than $25 \%$. Bankart repair depends on the presence of a capsule stretching and /or attenuation which is reported in patients with a chronic recurrent shoulder dislocation. The purpose of this study is to explain the technique that we used to reconstruct the labral defect in recurrent shoulder dislocation by using Biceps Brachii tendon as auto graft.

Methods: Four patients with history of recurrent shoulder dislocation underwent shoulder arthroscopy using the long head of Biceps as autograft in our department with average follow up 21 months (range,18 - 26 months) after the operation. All the patients had history of recurrent shoulder dislocation. We evaluated them according to clinical examinations and radiological investigations including X-ray and MRI. In this paper we explain our arthroscopic technique using long head of Biceps Brachii as a graft to cover anterior glenoid in cases of unreconstructedly labrum.

Results: The patients who underwent arthroscopic surgery using this technique had a significant improvement, pain free range of motion were normal forward flexion $170^{\circ}-180^{\circ}$, abduction $90^{\circ}$, external rotation with abduction $90^{\circ}$, with normal flexion of elbow, normal supination and pronation. Apprehension test post-operative was negative, and improvement DASH score 14.5 to 16.5 . The patients return to do their daily activities normally.

Conclusion: Using Biceps tendon as autograft to cover the labral defect will do the same work of the labrum to form a bumper by deepening the socket so the ball will be in its place, for this reason we repair the capsule and the Biceps tendon to restore shoulder instability with less side effects when comparing with conjoined tendon transfer and it is a simple procedure.
\end{abstract}

Keywords: Recurrent Shoulder Instability; Bankart Repair; Biceps Brachii Autograft; Latarjet Procedure

\section{Introduction}

Recurrent anterior shoulder dislocation is a very common problem that face the orthopedic surgeon, which affect young people in their life, specially the professional workers or athletes and military persons. They may need either arthroscopic or open procedure to obtain a stable shoulder $[1,16]$. Walch defines three groups of patients with shoulder dislocation. Group 1 is related to dislocation, which means at least one full dislocation that needs reduction by another person. Group 2 is subluxation, which means that the shoulder is not completely dislocated but with an anterior glenohumeral displacement confirmed by a physical exam. Group 3 is defined as an unstable painful shoulder, in which the doctor determines by examination that the cause of pain is shoulder instability due to labral detachment [17].

Arthroscopic Bankart repair is the most popular technique used, but there is a high recurrence rate in patients either with labral tear or glenoid bone loss more than 25\% [3]. Bankart repair depends on the presence of a capsule stretching and /or attenuation which is reported in patients with a chronic recurrent shoulder dislocation. Cadaveric biomechanical studies suggested that anterior-inferior glenoid bone loss, which accounts for $19 \%$ $21 \%$ of the glenoid, significantly compromises the stability of soft tissue repair alone [18]. On other hand, Latarjet procedure is used 
in patients with recurrent shoulder dislocation due to presence of bony defect [4]. The main aim of Latarjet procedure is to restore the shoulder stability by the sling effect which is provided by the conjoined tendon [5]. One of the disadvantages of Latarjet procedure is destroyed the coracoacromial arch which may result in superior instability $[6,7]$. There is a technique using the Biceps tendon as sling effect by transferring the Biceps tendon to the inferior part of glenoid. In our technique we fix the biceps graft anteriorly from the inferior part of the glenoid to the superior part with or without capsuloraphy. The main Indication of this technique "Khair technique" patients younger than 50 years who require external rotation with abduction movement of the shoulder during their works and have a capsule-ligament insufficiency. The aim of our technique to compensate the labrum to form a bumper by deepening the socket so the ball will be in its place. We believe that the contraindication of this technique is rupture of the Biceps tendon. The purpose of this study to explain the technique that we used to reconstruct the labral defect in recurrent shoulder dislocation by using Biceps Brachii tendon as auto graft. In this paper we explain our arthroscopic technique using long head of Biceps Brachii as a graft to cover anterior glenoid in cases of unreconstructedly labrum.

\section{Material and methods}

Four patients with history of recurrent shoulder dislocation underwent shoulder arthroscopy using long head of Biceps as autograft in our department, with average follow up 21 months (range,18 - 26 months) after the operation. We couldn't do more operation because of the critical situation due to the presence of covid 19 which decrease the number of the operations. All the patients had history of recurrent shoulder dislocation (three males and one female), the female patient underwent arthroscopic Bankart repair but within three months of the surgery her shoulder dislocated, and her doctors decided to do for her Latarjet procedure. While the male patients had recurrent shoulder dislocation. We evaluated the patients clinically and all have positive apprehension test, relocation test, and forced shoulder abduction and elbow flexion test (19). X-ray and MRI were done for all the patients, Xray shows either shoulder dislocation which reduced in the emergency department (Figure 1) or shows Hill Sachs lesion (Figure 2), MRI reported that they have Bankart lesion (Figure $3 \mathrm{a}, \mathrm{b}$ ). DASH scores were between 65 to 70 . The patients were undergoing shoulder arthroscopy to repair the labral defect during surgery. We found the labrum unrepairable severely for injured labrum (Figure 4), we decided using the Biceps tendon as autograft, as we informed the patients the steps of surgery and a consent form was signed for every patient. We followed them for an average 21 months, all patients have pain free normal range of motion even abduction with external rotation with no history of shoulder dislocation. They don't have weakness in flexion, also normal supination and pronation, there is an improvement of DASH score between 14.5 to 16.5 .

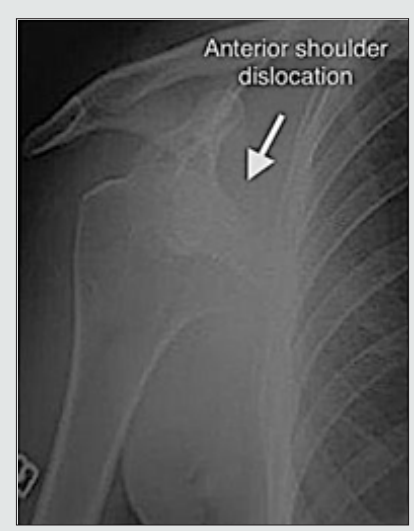

Figure 1: Xray show Rt shoulder dislocation and post reduction.

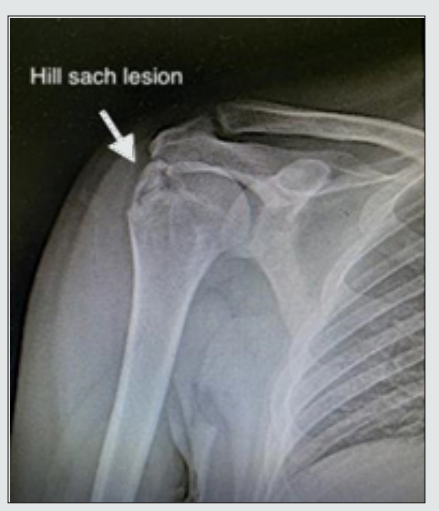

Figure 2: Xray show hill sach lesion with fracture at greater tuberosity. 


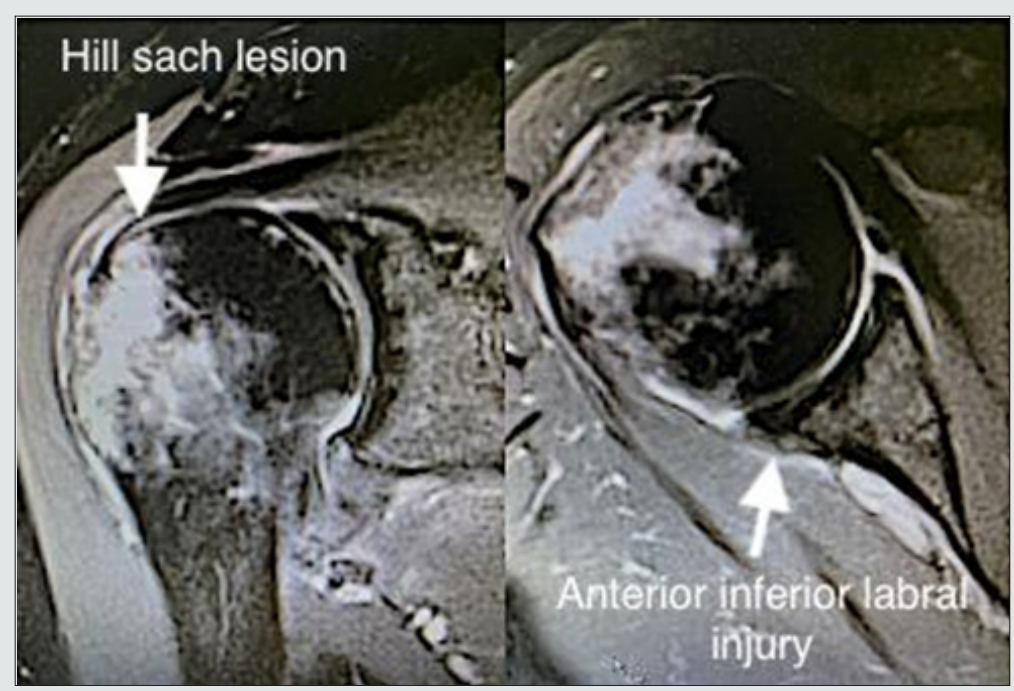

Figure 3: a,b,a MRI show fracture at greater tuberosity, b shows anterior inferior labral injury.

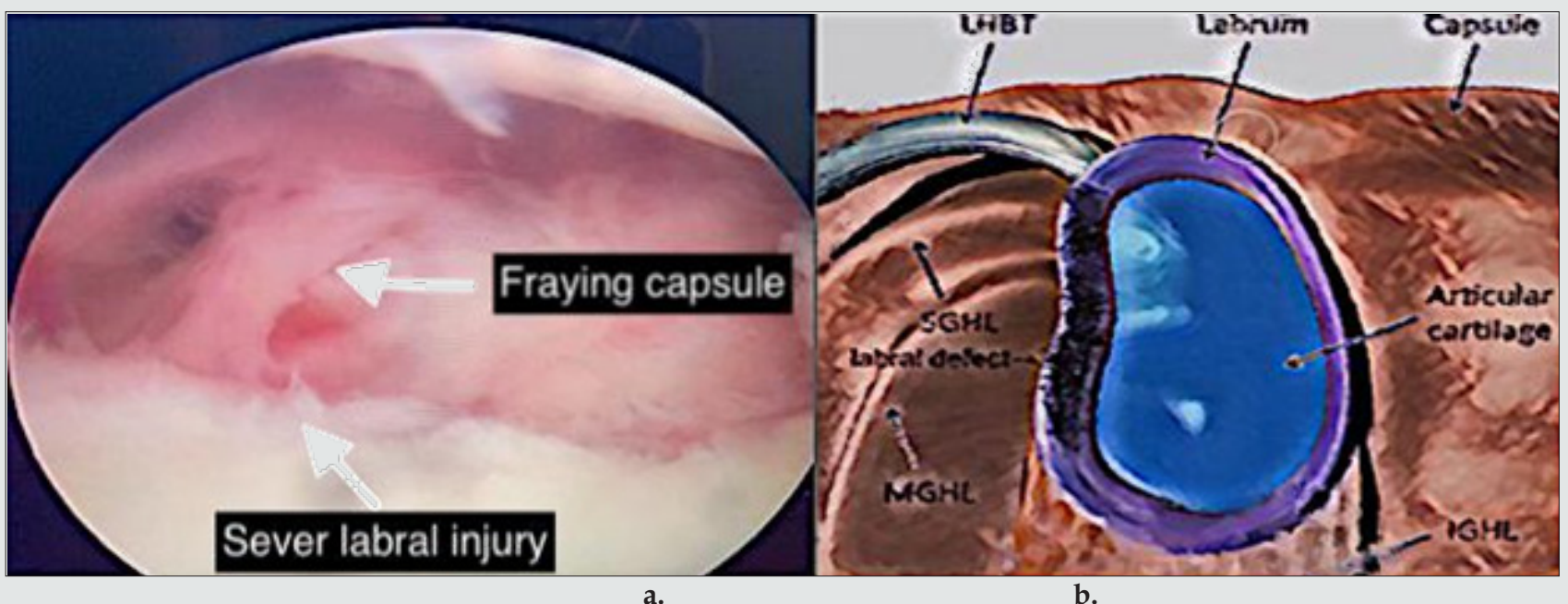

Figure 4: $a$, b show there is sever defect of the unreconstructable labrum.

\section{Surgical Technique}

This technique is performed by the main author, after general anesthesia the patient is positioned in lateral decubitus position, the arm placed in traction sleeve with $70^{\circ}$ abduction and $10^{\circ}$ forward flexion. A standard posterior arthroscopic portal and anterior superior portal using outside-in technique are created. Diagnostic evaluation for the shoulder. Once the labral injury is identified that can't be repaired, we also identified the situation of the capsule, then we use the liberator to prepare the glenoid and the radiofrequency is used for biceps tenotomy from the proximal part as proximal as we can. At this point, the capsule is grasped to be sure that we can shift it superiorly. A double loaded suture is inserted from the anterior portal on the face of the glenoid 1 to $2 \mathrm{~mm}$ from the glenoid rim at the inferior part at average 5 o'clock for the right shoulder and 7 o'clock for the left shoulder. A small incision was done on the anterior aspect of the shoulder used for inserting a grasper to retract the proximal part of the Biceps tendon to inferior part of the glenoid. A curved $45^{\circ}$ needle, spectrum hook is passed through the inferior part of the capsule and under surface of the Biceps tendon (proximal part of the tendon which is tenodyzed) $1 \mathrm{~cm}$ below the anchor, in order to obtain capsular shift. The shuttle or PDS suture is retrieved from the anterior portal and loaded with one of the anchor sutures and then the free part of the shuttle or PDS is retrieved the loaded suture. A simple stitch is done, and knot technique is performed depend on the surgeon preference. The same steps are performed for the second suture. These steps are repeated for the second and third anchors which increase the contact force between the capsule with the Biceps tendon and glenoid bone (Figure 5). Three of the patients required to do a capsuloraphy with the biceps brachii autograft. The fourth patients we used only biceps tendon autograft. Our idea to increase stability by using capsuloraphy with the biceps autograft. 


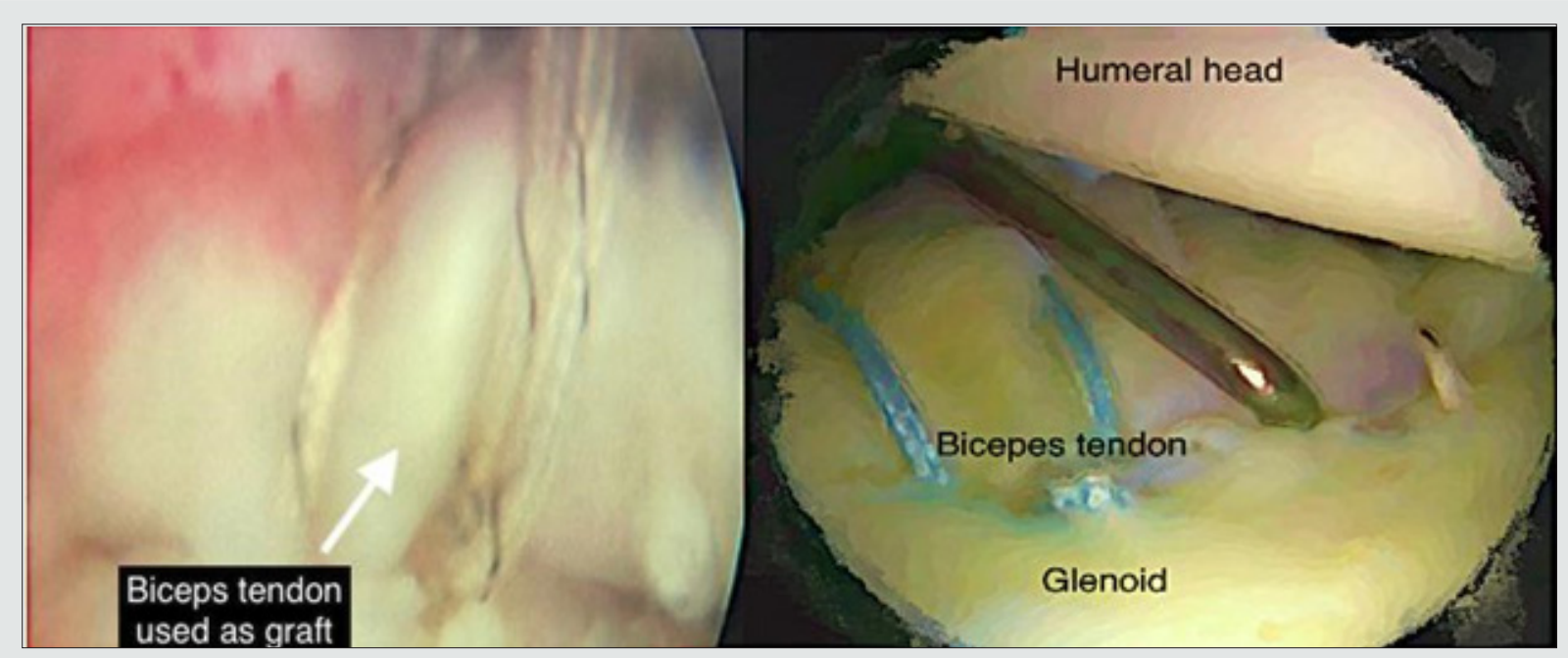

a.

b.

Figure 5: a, b shows the biceps autograft fixed in the glenoid.

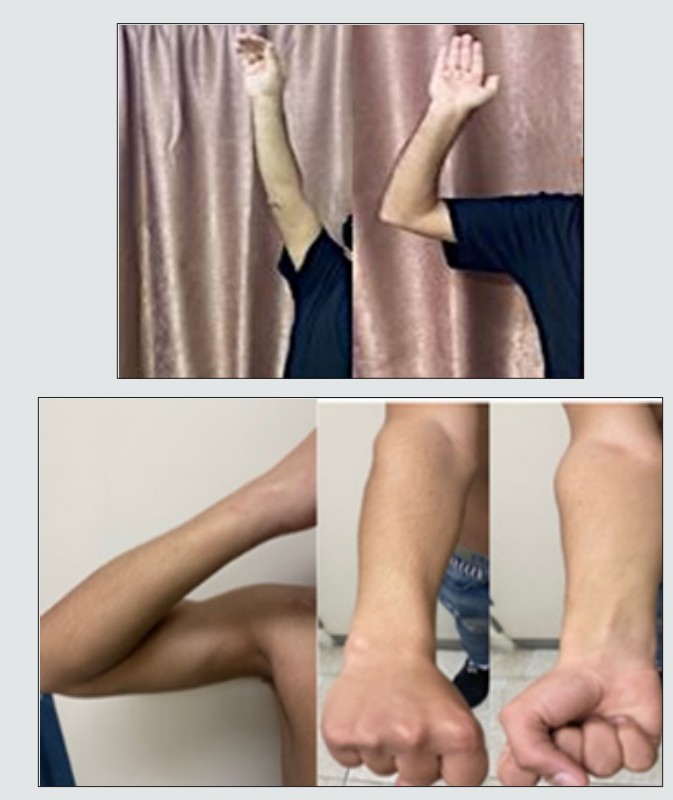

Figure 6: : a,b,c,d,e show the range of motion post operation.

a. forward flexion, b. external rotation with abduction $90^{\circ}$.

c. elbow flexion, d. pronation forearm, e. supination forearm.

\section{Discussion}

Recurrent anterior shoulder dislocation is a common pathology in active young patients, most of the cases treated surgically either by arthroscopy or open. Arthroscopy when there is detachment of the capsule -labral injury. Latarjet is a procedure for restore shoulder stability by the sling effect of conjoined tendon [8], in cases of significant bone loss of the anterior glenoid rim. Recurrence rate for the Bankart procedure alone range up to $37.5 \%$ among patients with poor labrum tissue or glenoid rim erosion or in high-impact athletes $[9,10]$ Many studies show that there are several factors which considered as a reason for high rate of failure as professional players who need forceful external rotation and abduction, younger age and those with soft tissue and bone defects [11,20]. A soft tissue procedure is also better tolerated when in contact with humeral head and avoid most of the complications of the coracoid bone attached to the glenoid like nonunion [12], graft resorption $[13,14]$ and graft migration ${ }^{12}$. One of the disadvantages of Latarjet procedure is destroyed the coracoacromial arch which may result superior instability [6,7]. Repairing the labrum and restoration of capsular tension should be done in same session to get more anatomic procedure and to reduce the recurrence rate $[15,16]$. 
The patients who underwent arthroscopic surgery using this technique have a significant improvement, pain free range of motion are normal forward flexion is $170^{\circ}-180^{\circ}$, abduction $90^{\circ}$, external rotation with abduction is $90^{\circ}$, with formal flexion of elbow, normal supination and pronation. Apprehension test post-operative is negative, and improvement DASH score 14.5 to 16.5 . The patients return to do their daily activities normally. This study describes a new technique that can be used in patients with unrepairable labrum and with small bone loss from the glenoid, which may help the patients to avoid other operations as Latrajet procedure. Repair of labrum and restoration of capsular tension should be done together so as to perform a more anatomic procedure and reduce the recurrence rate $[21,22]$. In our technique we use the biceps tendon to replace the labrum and restore of capsular tension to reduce the recurrence rate. The number of patients is low because of the situation of covid-19 and we closed the operation theater in our department for many times.

\section{Conclusion}

Using Biceps tendon as autograft to cover the labral defect will do the same work of the labrum to form a bumper by deepening the socket so the ball will be in its place, for this reason we repair the capsule and the Biceps tendon to restore shoulder instability with less side effects when comparing with conjoined tendon transfer and it is a simple procedure. We believe that the contraindication of this technique is rupture of the Biceps tendon.

\section{Compliance with Ethical Standards}

All procedures performed for this study were in accordance with the Ethical Standards of the Institutional and National Research Committee. This study was approved by the Institutional Review Board of our Institute. Written informed consent was obtained from all people included in the study.

\section{Acknowledgements}

Thanks to Royal Jordanian Medical Services for their support in providing surgical instruments and materials for this new technique.

\section{Conflict of interests: None.}

\section{References}

1. Lech O, Freitas JR, Piluski P, Severo A (2005) Luxação recidivante do ombro: do papiro de Edwin Smith à capsuloplastia térmica. Rev Bras Ortop 40(11/12): 625-37.

2. Burkhart SS, Debeer JF, Tehrany AM, Parten PM (2002) Quantifying glenoid bone loss arthroscopically in shoulder instability. Arthroscopy 18(5): 488-491.

3. De Wilde LF, Berghs BM, Audenaert E, Sys G, Van Maele GO, et al. (2004) About the variability of the shape of the glenoid cavity. Surg Radiol Anat 26(1): 54-59

4. Latarjet M (1954) Treatment of recurrent dislocation of the shoulder Lyon Chir 49: 994-997.

5. Young AA, Maia R, Berhouet J, Walch G (2011) Open Latarjet procedure for management of bone loss in anterior instability of the glenohumeral. joint J Shoulder Elbow Surg 20: S61-S69.

6. Lee TQ, Black AD, Tibone JE, McMahon PJ (2001) Release of the coracoacromial ligament can lead to glenohumeral laxity: a biomechanical study. J Shoulder Elbow Surg 10(1): 68-72.

7. Su WR, Budoff JE, Luo ZP (2009) The effect of coracoacromial ligament excision and acromioplasty on superior and anterosuperior glenohumeral stability. Arthroscopy 25: 13-18.

8. Dines JS, Dodson CC, McGarry MH, Oh JH, Altchek DW (2013) Contribution of osseous and muscular stabilizing effects with the Latarjet procedure for anterior instability without glenoid bone loss. J Shoulder Elbow Surg 22: $1689-1694$.

9. Hovelius L, Korner L, Lundberg B, C Akermark, P Herberts, et al. (1983) The coracoid transfer for recurrent dislocation of the shoulder: technical aspects of the Bristow-Latarjet procedure. J Bone Joint Surg Am 65: 926934.

10. Hovelius L, Sandström B, Olofsson A (2012) The effect of capsular repair, bone block healing, and position on the results of the Bristow-Latarjet procedure (Study III): long-term follow-up in 319 shoulders. J Shoulder Elbow Surg 21: 647-660.

11. Balg F, Boileau P (2007) The instability severity index score. A simple preoperative score to select patients for arthroscopic or open shoulder stabilization. J Bone Joint Surg Br 89: 1470-1477.

12. Boileau P, Thélu CÉ, Mercier N, Xavier O, Robert HC, et al. (2014) Arthroscopic Bristow-Latarjet combined with Bankart repair restores shoulder stability in patients with glenoid bone loss. Clin Orthop Relat Res 472(8): 2413-2424.

13. Di Giacomo G, Costantini A, de Gasperis N, De Vita A, Bernard KHL, et al. (2011) Coracoid graft osteolysis after the Latarjet procedure for anteroinferior shoulder instability: a computed tomography scan study of twenty-six patients. J Shoulder Elbow Surg 20(6) : 989-995.

14. Zhu YM, Jiang CY, Lu Y (2015) Coracoid bone graft resorption after Latarjet procedure is underestimated: a new classification system and a clinical review with computed tomography evaluation. J Shoulder Elbow Surg 24(11): 1782-1788.

15. Gartsman GM, Roddey TS, Hammerman SM (2000) Arthroscopic treatment of anterior-inferior glenohumeral instability. Two to five-year follow-up. J Bone Joint Surg Am 82-6A(7): 991-1003.

16. Sekiya JK (2005) Arthroscopic labral repair and capsular shift of the glenohumeral joint: technical pearls for a multiple pleated plication through a single working portal. Arthroscopy 21(6): 766.

17. Walch G (1991) The anterior recurrent dislocation of the shoulder. Rev ChirOrthop 77: 177-192.

18. Itoi E, Lee SB, Berglund LJ, Berge LL, An KN (2000) The effect of a glenoid defect on anteroinferior stability of the shoulder after Bankart repair: A cadaveric study. J Bone Joint Surg Am 82(1): 35-46.

19. Nakagawa S, Yoneda M, Hayashida K, Obata M, Fukushima S, et al. (2005) Forced shoulder abduction and elbow flexion test: A new simple clinical test to detect superior labral injury in the throwing shoulder. Arthroscopy 21(11): 1290-1295.

20. Cole BJ, Millett PJ, Romeo AA, Stephen SB, James RA, et al. (2004) Arthroscopic treatment of anterior glenohumeral instability: indications and techniques. Instr Course Lect p. 53: 545-558.

21. Gartsman GM, Roddey TS, Hammerman SM (2000) Arthroscopic treatment of anterior-inferior glenohumeral instability.Two to five-year follow-up. J Bone Joint Surg Am 82-A (7): 991-1003.

22. Sekiya JK (2005) Arthroscopic labral repair and capsular shift of the glenohumeral joint: technical pearls for a multiple pleated plication through a single working portal. Arthroscopy 21(6): 766. 
CC (P) This work is licensed under Creative

To Submit Your Article Click Here: Submit Article

DOI: $10.32474 /$ OSMOAJ.2021.05.000210

$\begin{gathered}\text { Orthopedics and Sports Medicine } \\ \text { Open Access Journal }\end{gathered}$
Assets of Publishing with us
- Global archiving of articles
- Immediate, unrestricted online access
- Rigorous Peer Review Process
- Authors Retain Copyrights
Orthopedics And Sports Medicine:
Open Access Journal

